\title{
The Import-Substitution Strategy of Economic Development: A Survey
}

by

\section{HenRy J. BRUTON*}

Over the past several years, the import-substitution strategy of development has been examined in considerable detail by numerous economists. For the most part, these studies have been concerned with one or another side of this many-sided approach to development policy. It now seems useful to review this literature in an attempt to isolate major themes and arguments and to try to put together a cohesive and comprehensive picture of where we stand now. This paper is not intended as a summary of the individual articles and books on import substitution, but rather is aimed at bringing together the theoretical issues and the empirical results that not only are of interest in themselves, but which also seem to add up to something that might legitimately be called an approach to development. To do this, I asked three general questions: 1) what appears to be the essential mechanics of import substitution as it has been practised in various countries that have been investigated; 2) what problems have emerged, and why, as a consequence of the conventional import-substitution (IS) strategy; 3) what has been found that suggests or leads toward an alternative approach to development that incorporates the good and eliminates the bad of this conventional approach.

The general conclusions that emerge from this survey may be summarized in the following way. Although the countries that have built their development policies around import substitution have experienced great difficulties, there are reasons to believe that a satisfactory approach to development can be built around this approach. The difficulties have arisen as a consequence of the activities selected for domestic development and of the methods employed to provide the incentives to bring about their development. Part of these difficulties arise from a view of the economic development process that now appears misleading, and part arise from assumptions about the developing economies that the empirical evidence shows to be unacceptable. More specifically, it appears that the distortions and misallocations that have been imposed on the

*The author, a former Joint Director of the Pakistan Institute of Development Economics, is at present associated with Williams College, Williamstown, U.S.A. The research for this paper was supported by a grant from the agency for International Development to Williams College, Mass., USA. The Agency is in no way responsible for any of the views expressed in the paper. 
economy by the conventional approach to IS have themselves created difficulties that contributed significantly to the widespread failure of the approach to work as satisfactorily as many expected. To repeat the previous sentence in a slightly different way: to implement their IS policy, countries have chosen instruments and techniques that seem, in effect, to prevent that very policy from being successful.

On the other hand, there are important aspects of the IS approach that appear most useful indeed. The concept of a strategy is useful, as is the idea of policies designed to create readily apparent investment opportunities. Similarly, the notion that new activities must be established in the developing countries is equally acceptable and equally important. What appears needed, then, is a way to achieve these advantages of IS without creating the distortions and misallocations that to-date appear so ubiquitous, and that appear responsible for itsfailures. The work on remodelling the IS strategy is just beginning, and its difficulties are more clearly understood than is where and how to modify it. This review, therefore, spends more time on the difficulties with IS than with more positive recommendations. The latter have, however, begun to receive attention and are implicit in many of the criticisms of the IS strategy as it has been used todate. It is important to keep in mind from the outset that the general thrust of the literature does not show that IS is necessarily futile. What emerges is not a recommendation for abandonment, but rather one for a more careful approach to its implementation.

Section I examines briefly the notion of a strategy of development in general, and the origins of an IS strategy in particular. Section II looks at the IS strategy first in very broad terms, and then at some of its more specific aspects. Section III considers some of the more positive results of our studies, and Section IV suggests a range of policy issues that are relevant, given the positive results. As noted, these policy issues are not discussed at length here as they have yet to be fully analyzed in the literature. This section, then, is something of a link with the past work and leads (hopefully) into future work.

Both terms, strategy of development and import substitution, merit attention at the outset. We will begin with strategy in general and work our way into import-substitution strategy in particular.

\section{A. Strategy of Development}

One may contrast strategy with theory of development in several ways. The latter term seems to refer to an explanation of the sources of growth - to increased capital and labour, increased productivity, improved resource allocation, demand conditions - and how these sources act and interact to produce 
growth. Development policies flowing from this kind of analysis are concerned with capital formation, saving rates, technical change, education, and similar items. One looks also at rates of return on alternative investment opportunities, and at using resources to maximize present value of future income streams. Emphasis is placed on the availability of these sources of growth, and how they may be used to produce an acceptable growth rate.

Strategy, a concept introduced into the development literature by Albert Hirschman [10], implies something a bit different. Specifically, it implies one (or both) of two things. In the first place, it suggests that by some twist or torment of the economy, or by some gimmick, the underdeveloped, stagnant economy can be set in motion. The primary obstacle to development is not the absence or inadequate supply of the source of growth. Rather, it is the absence of a catalyst that creates an environment or a circumstance that activates the already available, but unrealized, resources. Hirschman refers to a primum mobile, a prime mover, necessary to activate the latent growth forces. In investment allocation decisions, one looks not at rates of return on the capital projects themselves and present value of income streams accruing therefrom. One looks rather at whether or not a specific capital project may create circumstances which may be expected to induce further growth.

Hirschman's well-known book is perhaps the most explicit statement of this notion, but there are other arguments that employ essentially the same idea. The models of W. A. Lewis [16] and Ragnar Nurkse [18] built on the disguised unemployment assumption have this strategy notion at their base. RosensteinRodan's 'Big Push' [22] and Leibenstein's 'Critical Minimum Effort' [12] imply as well that supply limitations are not at the heart of the explanation of why an economy does not grow, and imply that if the economy is given a big enough catalytic effort, it will begin to grow.

In the second place, strategy is frequently used in discussions that distinguish between marginalism and structuralism, and may be seen most clearly with respect to the investment decision. This year's investment, small relative to the existing capital stock, may be allocated in accordance with conventional, marginal-productivity criteria. This small investment can increase output within the existing structure, but will not alter it. Yet, it is argued, the basic difficulty is a structural one. In general terms, structure in this context refers to the composition of output, techniques employed, import functions, land-tenure arrangements, educational system, class mobility, ..... of an economy. The policy objective, then, is not to so allocate investible resources that present values of income streams are maximized in the narrow sense. It is rather to use investible resources to create a new structure which, even with no increase in the quantity of resources, is presumed to yield a higher output than that possible within the existing system, and, what is more important, will permit continuing 
growth. In this context, strategy refers to an approach to development policy that seeks to modify the nature of the economy in quite fundamental ways on the assumption that such modification is necessary before sustained growth is possible.

This strategy of development is most clearly illustrated by the various works of Raul Prebisch and other Latin American "structuralists" [20], and the various arguments of Maurice Dobb [8]. The notion appears in more orthodox circles as well. In discussing India's development, I.M.D. Little writes: "Moreover it is very early for India to be able to guess where her comparative advantage will lie" [17]. A bit later in the same article, he says: "In a country as large as India with a wide complement of natural resources, it would be surprising if it did not turn out to be economical for India to produce a little of almost everything". In both these statements, Little is saying that in some future after India has changed her structure into some normal (?) optimal (?) state, then she will allocate resources in a manner to maximize in the conventional fashion. In the meantime, presumably some (unstated) alternative criteria of allocation is to be used. Similarly, in many of the instances where one reads that a country needs or requires specific capital items (usually contrary to the dictates of conventional maximizing procedure), the argument implicitly rests on some notion of a changed or new structure to be established.

These two bases of strategies are not mutually exclusive. An incentive to change the structure can be used as a means of establishing a prime mover. And the objective of a policy or a strategy may indeed be to accomplish both. At the same time there are advantages in keeping the ideas distinct, and reference will be made to both origins, a prime-mover origin and a structurechanging origin, of strategies.

Consider now more specifically import substitution as a strategy of development. To a very large extent it was arrived at by default, and is not only the most common (frequently observed) strategy in practice, but it is indeed perhaps the only one. This is true partly because IS encompasses some other possible strategies and partly because it is easily initiated. Indeed, it seems clear that most developing countries tend to slip into an IS approach to development. In this case, then, IS is not a strategy in the sense of a carefully planned approach, but rather a situation into which a country tends to find itself as the development effort is made.

It is this ease of initiation that seems to be the major (but not exclusive) source of the prevalence of IS's popularity. To curtail imports in order to create investment opportunities or to change the structure is a relatively simple matter ${ }^{1}$. If a country decided on an export-promotion strategy, however, it is

1Note that it is the initiation of IS that is stated to be "easy", not its effective implementation. A principal aim of later sections of this paper is to examine the implementation question. 
not so evident how to begin. Similarly, to build a development strategy around industrialization without IS does not lend itself to an obvious set of policies. The same may be said of a strategy built around increasing agricultural productivity.

One may, then, visualize the origins of IS in somewhat the following way: policy-makers become aware (or convinced) that conventional optimizing criteria cannot (do not) lead to policies that produce as rapid a rate of growth as desirable either because the need for an explicit prime mover or because the existing structure of the system is (or is thought to be) alien to growth. The policy-maker then searches for an alternative guide to policy-making - one that will step up the rate of investment and create a larger number and more obvious investment opportunities. Even if it is assumed that a number of strategies are examined, the IS strategy is likely to be selected because it apparently calls merely for keeping out imports, a task most governments can be expected to accomplish. The fact that the country is likely to be experiencing balance-of-payments difficulties adds to the attractiveness of this approach. Also IS will create gaps in the economy where very obvious investment opportunities exist, thereby creating the kind of situation that will generate Hirschman's primum mobile. Finally, the IS policy will keep out goods previously imported, thereby encouraging their domestic production, and thereby (again) contributing to structural change. Such a strategy would then seem to meet all, or at least a wide range, of difficulties believed to be blocking development.

That few policy-makers have, in fact, systematically surveyed the range of policy opportunities and concluded that IS is the best hope is not especially important. That they have in fact most often backed into such a policy to meet a balance-of-payments (or some other) crisis is indeed not inconsistent with the preceding arguments. It merely means that the situation that precipitates action is a crisis, not that the crisis is the rationale of the action taken.

\section{B. Import Substitution}

Import substitution has a variety of meanings in the literature, and a frontal attack on a simple definition is no small undertaking [25]. When attention is limited to a single product, there is little difficulty. Here IS refers to a policy that reduces or eliminates entirely the importation of the commodity and, hence, leaves the domestic market exclusively for domestic producers. Measures of IS that are based on changes in the ratio of imports of specific products to their total domestic absorption are of course concerned with this definition. Difficulties emerge when we seek to aggregate. A policy that reduces the proportion of the quantity of a product that is imported may, at the same time, increase that proportion for another product. Whether the policy in this case should be called IS becomes ambiguous. Similarly, changes in the 
aggregate import-GNP ratio may hide the impact of IS policies on specific sectors. It is a bit misleading, therefore, to rely on changes in the aggregate ratio to identify the effectiveness of IS policies aimed at changing the proportion of total absorption of a good that is imported.

The issue can be put into an understandable framework by identifying the objective of IS policies that are aimed at reducing imports of specific commodities. Few policy-makers actually wish to shut out all imports. Rather, as already noted, the objective is structural change or some kind of investmentincentive-creating idea. Part of the rationale of the structural-change objective is that the existing structure makes the economy undesirably dependent on matters outside its own control. One of the guides to action, then, is how can the structure be changed so that the economy is less at the mercy of its foreigntrade activities? The extent of the achievement of such an objective is not easily measured at all, and certainly not by means of changes over time in the import-GNP ratio.

The picture then seems to be this. Developing countries have not achieved sustained growth because of their structure or their lack of a prime mover. The IS strategy to change this structure and to provide a primum mobile is to replace imports by domestic production of certain commodities. Thus, IS in the narrow sense is limited to specific activities and is measured by increases in the ratio of domestic production to total domestic absorption. In the broader sense, import substituting within individual sectors is a means to the more far-reaching objectives just stated. These latter objectives mean that the long-run success of IS rests heavily on the specific sectors in which import substitution is carried out, and the methods chosen to bring about their domestic expansion. An analysis of the IS strategy of development, therefore, involves an examination of the rationale of the selection of these activities, and the consequences of the methods and policies used to bring about the import substitution. On this latter issue, interest is primarily directed toward the effect of these policies on the growth of the economy.

II

In this section, we first examine the broad pattern of IS as it has evolved over the last several years or so. Then, we look at a number of features of this pattern that stand out in the broader, overall picture. In the following section, we try to establish a series of positive conclusions that follow from this discussion of the main characteristics of the IS model.

\section{A. The General Nature of Import Substitution}

As noted in Section I, the immediate approach of an IS policy is to replace imports of specific activities with domestic production. Without a doubt, the simplest way to do this in a market economy is to impose limitations on imports. 
This limitation on imports has a variety of impacts [19]. It creates gaps in the economy that make for obvious investment opportunities in nontraditional activities of the economy, usually manufacturing. Resources are then directed into new industrial channels (structural change) and the capitalist sector is enlarged. In the latter sector, expected new profits may lead to an increase in the saving rate and to further increases in investment, as capitalists are assumed to be high savers and accumulators. The new capital goods are imported and are paid for with the foreign exchange released by the reduction in the imports of the commodities whose domestic production is being encouraged. In this simple picture, two not-so-simple questions arise: what markets should be sealed off from foreign competition and what method should be employed to seal them off. Most of the literature under review has something to say directly or indirectly on these two issues. Consider first which products to protect.

In practice the answer is consumer goods in almost all countries. This is certainly the case at the outset of the IS process. There are several reasons for this concentration on consumer goods.

The simplest reason is that the cost disadvantage between domestically produced and imported consumer goods is less than for capital goods or for intermediate goods. Thus, it appears to policy-makers that by preventing the importation of consumer goods, the advantages of IS can be achieved at minimum costs. The cost argument is supplemented by the existence of an obvious demand, i.e., the consumer goods are being imported, while the dimand for capital goods, intermediate goods, or raw materials depends on the mounting of an investment programme. Finally, consumer goods (especially durables) are universally deemed inessential to development, and an increase in their costs and in their prices assumed to be less harmful than increases in the prices of capital goods. The latter goods are, thus, imported with few impediments and frequently at exchange rates that greatly understate their costs to society. Thus, not only is the domestic production of capital goods discriminated against by the tariffs and exchange-control policies, but also by exchange-rate policies that keep their imported costs below real costs. The rationale of these latter policies favouring the importing of capital goods rests in general on assumptions as to the essentiality or to the strategic role of physical capital in the development process. The relatively low tariff rates on raw materials and intermediate goods mean further that the protection afforded the value added of many consumergoods producing activities is markedly higher than the rate of protection on the good itself would indicate. Hence, both the extent of protection afforded a given activity and the extent of the cost disadvantage of that activitiy probably are understated by an examination of nominal tariff schedules.

This first stage of the IS process ends when the expansion of finished consumer-goods capacity hits the limit of the domestic market. At this point, 
the economy has a number of new activities whose survival depends on some form of protection and whose expansion cannot continue. Further, growth, then, must take place in activities which are now importing or the recently established IS activities must enter the export markets. When this second stage is reached the hurdles the developing country must surmount seem to rise for a number of reasons.

1) Since this second stage is difficult (and the first so easy), the first stage is extended to its maximum extent. Thus, protection is provided on as wide a range of consumer goods as possible. One gets, then, what David Felix [9] has called "premature widening" of the productive structure, i.e., an expansion into a large number of relative small-scale activities rather than a concentration on a few. Advantages accruing from scale effects are at best limited to a handful of activities, and may well be absent entirely.

2) If IS is to continue, the economy must move more heavily into intermediate- or capital-goods production. This shift not only raises the direct cost of growth (the cost of the domestic production of capital goods or intermediato goods is larger relative to their import costs than is the case with respect to the consumer goods for which domestic supply has already replaced imports), but it also affects the costs of production and the level of existing protection on the new consumer-goods industries. Evidently, if a new producer of consumer goods had been using imported intermediate (or capital) goods in the first stage, and is now forced into using higher cost (and probably lower quality) domestically produced inputs, his production costs will rise. Similarly, at the prevailing tariff rates, protection on the value added of consumer-goods activities will decline. To maintain the same level of protection on the original IS consumer-goods activities, therefore, requires an increase in the rate of protection. This pushes up the cost in these activities, and (barring devaluation) thereby lessens their chance of exporting.

3) At the same time that investment costs are rising, at least two other developments are occurring that tend to reduce the country's saving capacity. As the economy expands its domestic production of consumer goods, their prices may fall relative to those of domestically produced capital goods [19] and income probably shifts away from government as customs duties decline [14]. In the second place as the domestic output of consumer goods rises so too does demand for foreign exchange for the importation of spare parts and rawmaterial inputs, not all of which can be produced domestically. If these inputs are not forthcoming, underutilization in the consumer-goods sectors appears. The evidence of this underutilization creates obvious pressure for increasing consumption simply because, if the capacity to produce consumer goods exists, it would appear nonsense not to use it. To use it mcans of course to reduce the saving rate below that which might be achieved [11]. To maintain the saving 
rate in these circumstances will not produce investment because there is no way to use the resources released from producing consumer goods to produce capital goods, i.e., capacity built to produce consumer goods cannot be used to produce capital goods [26] and exporting is not possible because of high costs. Added to these two reasons is the possibility that the misallocation imposed on the economy by the IS policies will reduce total output below the level it would have reached in the absence of such policies, and hence total saving would tend to fall even if the saving-income rate remained constant.

The outcome appears rather clear: at the very point that the economy must save more in order to maintain its rate of growth of capacity, it has major incentives and pressures to reduce that rate. Essentially, the choice of conconsumer goods - or the investment criteria of least disadvantaged - as the items to import substitute for leads to developments that dampen and may eventually halt the growth that the original protection induced. These growthdampening effects have to do with investment moving into new areas of higher costs - consequent to the failure of the new activities to enter the export market - at the same time that saving declines.

This is not, however, the end. There is the further question of the complications arising from the nature of the protection afforded the newly created activities. The most common protection package consists of two aspects: 1 ) an exchange rate that undervalues foreign exchange and adds extra burdens to the effort to enter the export markets. As already noted, the usual rationale of such a policy is that it keeps the price of imported investment goods relatively low and so encourages investment, plus the assumption that foreign demand for most export items is assumed to be inelastic. 2) If foreign exchange is undervalued, then of course equilibrium in the balance-of-payments must be achieved by means of tariffs or the direct licensing of imports or both.

The overvalued local currency may encourage investment, but it has other characteristics much less likely to facilitate growth. It makes for a capital intensity in production higher (due either to choice of technique or to choice of product) than would be the case if foreign exchange were priced right. It thereby dampens the employment effect of the IS activities. It also creates a level of import intensity in production that is incompatible with foreignexchange-earning power, i.e., it penalizes export competing and increases the need for imports. Further distortions are imposed by the tariffs and licensing necessary to keep the balance of payments under control. And as tariffs rise and exchange controls become more rigid, for the reasons already noted, the distortions increase. As the latter occurs, supply bottlenecks appear and the economy's capacity to transform its resources into capital (or other) goods and services is increasingly impaired. These developments are hardly conducive to sustained growth. 
The picture just described is perhaps a bit extreme when applied to any one country, but the basic pattern seems applicable to a wide range of countries in Latin America and Asia. To summarize briefly: an IS strategy imposes a necessity of selecting activities to protect and conventional selection procedures have left a residue of high cost, nongrowing activities in many countries. Added to the problem of the selection of activities is the method of their protection. Again, conventional procedures have left a residue, this time of distortions which seem to increase as IS is pursued. We usually think of distortions as simply resulting in a lower level of output than would be possible with no distortion. This it surely does, but there is evidence of a much more important consequence, namely a major reduction in the capacity of the economy to maintain its growth of output in the manner noted above. Clearly then, a successful IS policy must find ways to select the right activities to protect, and must protect them in ways that will not so distort the system that growth is effectively thwarted.

\section{B. Some Specific Aspects of Import Substitution}

In order to consider how these latter objectives might be accomplished, it is helpful to look more closely at some specific results that conventional IS practices foster and which seem to be especially damaging. This will enable us to emphasize as well a few hints as to how such effects might be avoided.

These points may be considered under the following headings:

1) A structure of production emerges in which it is impossible to use all available capacity without large-scale capital inflows. The argument is clearest if one assumes that prior to the construction (or purchase) of the capital goods, there exist several options as to techniques of production and to choice of product to produce, but after construction both technique and product are fixed. At the time of investment (of the construction of the capital) the consequences of import-substitution policies are reflected in import prices (essentially of capital goods) that are below the costs of producing the exports to buy the imports, in the underpricing of domestically produced goods, and in the thorough protection from outside competition. In such a situation, investors have numerous incentives to choose a product and a technique to produce it that are incompatible with relative supplies of inputs. Thus, a structure evolves that can function efficiently only with a rising flow of imports. The growth of exports, however, is discriminated against by the very same factors that produce the alien structure. Unless then a rising flow of unrequired imports is available, we will eventually see underutilization appear. Given an existing alien structure of this sort, correcting the source of the distortions (by devaluation, raising the price of capital, labour subsidies, etc.) will not immediately eliminate the difficulties unless one is willing to assume that technique and product-mix can be adjusted on existing physical capital in a rapid and painless way. Indeed, seeking to correct the distortions in these ways can exacerbate the problem, e.g., devalua- 
tion may lead to inflation, raising interest rates reduce investment. If the latter events do occur they may drive policy-makers to more direct controls which add to the distortions. An important by-product of the same policies that produce the underutilizations is that they also result in a rate of increase in labour employment that, independently of the level of utilization, is well below that which might be achieved with different policies.

2) The above developments lead to the position that specific shortages are brakes on development. Thus, Gordon C. Winston [26;27] suggests that a capital-goods sector can be too small given the potential saving rate and export capacity. In [26], he offers evidence to support the view that in the early years of the Pakistan development effort, the size of the capital-goods sector did seem to be the limiting factor in that country's growth. More generally, the IS strategy leads to the development of an economy whose various sectors are consistent and are feasible only by fluke as the mechanisms for creating and maintaining structural consistency have been destroyed by the IS policies.

External aid may then be claimed on the grounds that if the specific shortage is relieved by aid then the capacity made idle by that shortage will be brought into use, and the economy will in consequence begin to grow very
rapidly [5]. This result does hold for a given period, i.e., for a situation already
distorted. But aid that simply provides the missing input can distorted. But aid that simply provides the missing input can in fact do more
harm than good. It can enable the economy to harm than good. It can enable the economy to continue to function despite the existence of the distortions, i.e., aid can be used only to permit the economy with. Aid used in this way may hinder the correction of the distortions or even
wingerin knowledge of their existence [4]. Aid used to permit correction of the sources of distortions will have a much more permanent effect on the growth capacity. In order to use aid in this way, however, the distortions must be barred, their origins understood, and their method of elimination known.

3) A further complication arising from most approaches to IS has to do with the extent and sources of the distortions imposed on the economy. This issue is seen most clearly in terms of tariffs and indirect taxes. A tariff on the imported product plus any sales tax on the imported product less any sales tax on any domestically produced competitive product provides an initial approximation to the extent of "nominal protection" [13]. The extent to which a process (in contrast to a product) is protected depends as well on the "nominal protection" afforded the inputs used by the particular process and the indirect taxes on these inputs. Similarly, the not uncommon overvaluation of the domestic currency adds a further element that must be introduced as one tries to untangle the consequence of (e.g.) tariffs and indirect taxes. Less evident, but no less important, is the fact that the several markets in an economy vary markedly in the extent of their competitiveness, in their pricing policies, and in the extent 
that they absorb or pass on taxes. There are two main consequences of all this. In the first place, consideration is almost always limited to the specific target actually aimed at with the given instrument. Rarely does one find evidence of an examination of the many policy instruments that act on the same target, and that act on the efficacy of the specific instrument under consideration.

The second place follows from the first place, namely tracing out the consequences of a single policy - e.g., understanding the distorting effects of a tariff - can be extremely difficult, even practically impossible. This issue is particularly relevant in a situation where policies (tariffs) that would, under some circumstances, distort are instituted to correct another policy (overvaluation) that also distorts. In developing countries where the price system does not (or is assumed not to) work effectively, and hence direct controls are widely used, this point has considerable practical relevance.

The studies of the structure of protection by Stephen R. Lewis [13] and Paul G. Clark [6] shed considerable light on these issues. They try to estimate empirically the extent and nature of protection by correcting the nominal tariffs for indirect taxes, input taxes, and overvaluations. The computations worked out for Pakistan [13] and for Brazil [6] and the discussion of Mexico [21] show substantial differences between the nominal tariff rates, and these rates modified to take into account overvaluation, indirect taxes, and all the rest. Similarly, the Lewis study shows that one sector may also be protected by virtue of discriminatory government policies against another sector. In the case of Pakistan, the agricultural sector is estimated to have (in the early 1960's) received about 35 per cent less when trading domestically than it could have received if it traded in the international market. This disadvantage of the agricultural sector, the chief supplier of wage goods to the manufacturing sector, contributed to keeping real wages for manufacturing workers favourable, and hence to keeping wagecost pressure in the manufacturing sector modest.

Evidently just looking at the tariff schedule on final goods does not enable one to predict its consequences in terms of investment allocation. Similarly, correcting distortions due to tariffs requires more information than simply the tariff schedule. It also means that a wide range of policies must be seen in the context of existing policies, and examined in the context of whether these existing policies are institutional constraints or are themselves subject to manipulation. The unravelling of all this in an economy with widespread indirect taxes, direct controls, import and investment licensing, and an overvalued currency is obviously a task of considerable magnitude, and one that does not lend itself to simple formula.

4) Underlying the IS approach to development is the notion of an economy that is, as noted in Section I, to be altered. In this sense then invest- 
ment is aimed at creating a new and different structure that is consistent with the achievement of this objective. Most of the new activities cannot be operated domestically at rates competitive with similar activities in other parts of the world, and hence protection of some sort is required. Implicit in much of the policy-making of IS is the assumption that costs in the new activities will decline and a new structure will emerge whose routine functioning produces a rising GNP. The argument may be put this way: the products produced and the techniques employed in the developing countries are becoming increasingly obsolete. This fact is reflected most clearly, but not exclusively, in deteriorating terms of trade. The country then has a choice with respect to the allocation of its investments: it may put its new resources into traditional activities which are facing increasingly unfavourable terms of trade, or it may put them into new activities that are currently operated at costs well above those that prevail abroad. If it chooses the latter, it must be with the expectation that costs will fall secularly, and at some point the new structure would be composed of activities that can meet world competition [2]. Evidently, then a key question has to do with the rate of fall in costs, i.e., the rate of growth of productivity, in the IS activities.

The evidence developed in $[1 ; 3]$ suggests not only that productivity growth has been generally low relative to that achieved in advanced countries 2 , but also that the very policies designed to implement the IS approach have been significantly responsible for their poor showing in the productivity growth race. To repeat a point made earlier, to implement their IS policy, countries have chosen instruments and techniques that seem, in effect, to prevent that very policy from being successful. Evidence on this latter point is not without ambiguity, but the kind of distortions noted under item l) above appear at the heart of the explanation. Added to this is the existence of a situation in which it is generally impossible to exploit economies of scale, in which competition is lacking, and in which the imported technology is unsuitable to factor endowment. More generally, one may say that the failure of the conventional IS policy package to take into consideration the strategic role of productivity growth has resulted in it being not only ignored but discriminated against in the same sense that exports and a domestic capital-goods activity are penalized.

The neglect of productivity growth can in part be traced to the widespread acceptance of a growth model in which physical capital formation is at the heart of the growth process. In paying primary, if not exclusive, attention to physical capital formation, the policy-maker neglects not only that (productivity growth) which is crucial to the success of an IS strategy, but, as many studies have shown,

2Productivity growth here, and elsewhere, refers to labour productivity or "total" (labour and capital) productivity. 
that which is responsible for well over half of observed GNP growth in all currently rich countries.

5) Finally, it is useful to mention a few rather more specific consequences of most IS policies. Most developing countries depend quite heavily on import duties as a source of government finance, and as consumer-good imports usually carry a high tariff relative to capital goods, the complete protection of the former can contribute to a government finance problem [14]. It indeed may do more. Since income taxes are difficult to enforce, an IS strategy may push the government into greater reliance on excise duties, and possibly export duties, as a means of acquiring finance. A second point that merits a specific note has to do with the effect of IS on the trade balance. There is little evidence that even hints that the trade balance improves as a consequence of IS policies. This is surely the case in the short run, but seems true as well in the longer run. This is partly explained by the widespread tendency of IS policies to discriminate against exports, but also by the failure of IS to reduce imports or importGNP ratios, i.e., IS policies do not reduce the demand for imports. This point comes through in many papers, (see, especially [23]).

Following on the heels of this evidence is the point that as the composition of imports changes from heavy concentration on consumer goods to emphasis on capital and intermediate goods, the economy becomes increasingly vulnerable (as to the maintenance of the level and the growth of output) to interruptions in the flow of imports. For example, curtailing the imports of 1000 dollars of shirts will have less impact on an economy than will the curtailing of 1000 dollars of chemical cellulose used in the manufacture of shirt material [25]. A corollary of this point and indeed all of the points mentioned here is that the economic structure that the IS approach to development spawns is no more flexible and adaptable than the one that is sought to be replaced. Flexibility, adaptability, responsiveness are attributes the advantages of which are disputed by no one, and their acquisition is part of the goal sought after. Again, however, the evidence shows that policies aimed at this goal have the opposite impact and tend to solidify the structure rather than to grease the wheels on which it operates. Although little evidence exists that helps our understanding of why some economies appear much more flexible and responsive than other economies, the evidence does suggest that the very alienness of the imposed new structure does play a relevant role [3].

A simple example may illustrate this point. A machine imported by a low-income, nongrowing country not only creates a required flow of imported spare parts and raw materials, but it can also impose new skill demands, supply and marketing demands, work attitude and organizational demands. This latter group of demands is such that the importing economy cannot respond quickly and easily to meet effectively a situation other than that called for by the 
exact formula envisaged in the operation of the new machine. The situation is somewhat similar to a firmly established, well-groomed bureaucracy that works splendidly as long as the routine is uninterrupted, but virtually collapses when a file goes astray. In the same sense, an economic structure created by conventional IS policies is so incompatible with the rest of the system that adjustments to changes in demands, in technology, in any part of the routine are accomplished painfully, if at all.

The five preceding categories of characteristics seem to be inherent in the IS approach. Obviously, this package does not apply en toto to all the various countries that have been researched. It would be correct, however, to insist that the range of issues just reviewed reveal accurately the nature of the consequences of a widely employed approach to development. It is quite evident how and why these consequences can slow up the growth of GNP, can reduce productivity growth, can increase the need for rising levels of aid, can impede, indeed reduce, the extent to which the economy can exploit its domestic resources, can in fact create a situation that finds continuing development virtually unachieveable. Also, evident in the above list are ideas and arguments that lead to reformulations and modifications that suggest alternative approaches to development and alternative sets of policies. These positive results may be considered a bit more explicitly now.

\section{III}

Our positive results may be considered under three broad headings: distortions, productivity growth, and what earlier was called alienness.

\section{1) Distortions of IS Policies}

The most pervasive impact of IS policies has been that it distorts the economy, and these distortions do not, except in rare instances, correct themselves. Indeed, as shown above, economies become increasingly distorted as the IS process continues. Three assumptions seem to underlie much of the analysis that leads to the policies that in turn produce the distortion. One has to do with the assumptions about the responsiveness of the various sectors of the system to relative price changes, the second to the existence and impact of external and internal economies that accompany the establishment of new activities, and the third to the role of capital formation in development. If one assumes that relative prices have no effect on anything then they can be safely ignored, and distortion loses much of its meaning. Consequently, the policymaker can ignore the impact of misleading price signals on his economy. Similarly, if expected external (or internal) economies are assumed great enough, then any activity can be justified, and there appears great, and unsupported, optimism implied by many policies as to the existence of such economies in the newly established activities. And, an assumption seems to prevail that amounts 
essentially to the assertion that a high rate of physical capital formation can overcome any obstacle. Evidence from several of studies strongly suggests that none of these assumptions can support the weight that it is asked to bear.

The most specific evidence on the role prices can play has to do with foreign trade. In [24], for example, John Sheahan presents regressions that leave little doubt that maintaining reasonably correct exchange rates does have a significant effect on export earnings from Colombia's exports other than coffee and oil. In [7], Paul Clark's equations explaining Brazilian imports show price elasticities ranging from -.35 for capital equipment to -1.62 for the construction material industry. While elasticities with respect to investment (the stand-in for GNP) were higher than the price elasticities for four of the six groups for which both investment and price elasticities were available, this evidence indicates again that sufficient substitutability between domestic and imported goods exists in Brazil, that to ignore it will induce distortion. The extent to which the Colombian and Brazilian equations represent demand or supply parameters can not be told from either set of equations. Doubtless to some extent both are effective so that the computed coefficients are probably not estimates of a structural parameter. Nevertheless, these results do indicate that a price effect does exist and which in turn indicates substitutability and responsiveness in the economies of significant magnitude.

There is evidence on this issue on a more general level. In a study of Mexico [21], Clark Reynolds suggests that postwar policies were somewhat different from those of many other countries. Nominal tariff rates have been much lower than in most other developing countries, and have risen only moderately, if at all, since the 1930's. Also the more established firms have to supply products of reasonable quality and at a reasonable price within a few years of their initiation or their protection is reduced. The findings on Mexico also indicate that considerable substitution exists between domestic skilled labour inputs and imported intermediate goods. Finally, Mexico's IS activities appeared more heavily concentrated in labour-intensive industries than has been the case elsewhere. (Though this latter is not necessarily a desirable condition, it appears to be so in this case.) Evidently, Mexico's relatively strong showing since 1950 is explained by a great number of factors and cannot be attributed exclusively to the points just enumerated. It is, however, appropriate to emphasize that these attributes of Mexican policy did prevent the marked distortions from appearing that would impede the other advantages of Mexico from having their full effect.

A last example has to do with Pakistan. In Chapter VII of [13], S. R. Lewis' discussion of the effect of economic policy on the growth rate and composition of output shows that policies that tended to correct the distortions in the system did produce changes that resulted in a more efficient use of both 
domestic and aid-provided resources. Both the Export Bonus Scheme and the import-liberalization policies seemed to affect allocations in a manner that facilitated a more rational use of her resources. Other policies examined by Lewis to some extent offset these effects, but the point remains relevant.

On the question of external effects, the evidence is less clear and, what there is, is of a more negative kind than that just mentioned. It is surely clear that structural change itself does not automatically contribute significant external economies. There is virtually no empirical evidence that the often referred to, seldom specifically identified, "external" effects of new activities - labour training, technological improvement, economies of scale, etc. - occur with the establishment of import-replacing activities. Indeed the same distortions that result in activities in the developing economies being less productive than in the advanced countries also have negative effects on the realization of possible externalities. More positively, one may say that these matters must be considered explicitly with respect to individual activities, and general assumptions as to their sources are not acceptable. This is not to suggest that structural change as an end in itself may not be important. It often is, and rightly so. The point here is to emphasize that our studies do not show that such changes do, in themselves, bring about major external economies.

The third implicit assumption underlying much of IS philosophy has to do with the role of capital formation in development. This is a broad question which our studies do not directly consider. The evidence is now overwhelming that merely more investment does not mean a higher growth rate. This does not mean of course that capital formation is not important in producing growth. It does mean that merely generating a high rate of investment is not sufficient to assure growth. More specifically it means that a higher rate of investment will not in itself solve - or prevent from arising - other, growth-defeating, issues. A still more important conclusion, noted in several studies, is that concentrating attention on capital formation irrespective of other matters creates growthdefeating developments.

These arguments have two broad categories of implications. In the first place they mean that distortions are very real and must be taken into account in devising and appraising policies. For example, if there were no substitutability between labour and capital (and among products), then the relative cost of labour and capital would not be relevant to the distortion issue. Efforts to affect the distribution of income via wage policies (minimum wage rates, high severance pay, etc.) will have no effect on choice of technique or product selected. Where there is such substitutability, however, these policies do introduce distortions. Similarly, if the exchange rate's role as an allocation device is negligible, then to undervalue foreign exchange to encourage investment is acceptable policy. If, as now seems clear, the exchange rate does perform an allocative 
function, then to keep it below its equilibrium level does impose distortions, the damage of which cannot be overcome by the mere fact of a high rate of capital formation. In general then, we can say that the degree of flexibility and adaptability suggested by recent studies shows that many policies aimed at specific targets do impose distortions on the system that make it difficult or impossible to achieve the specified target.

The second implication is even broader than the first and follows from it. The results suggest that the misallocations produced by conventional IS policies not only reduce total output below the level that it might have otherwise reached, but it also reduces the growth rate, principally through its effect on productivity growth and the flexibility of the economy. This means simply that the distortion issue is a most strategic concept, strategic to the point that to ignore it is to court failure. This we believe to be a vital point, and more will be said on its specific policy implications later.

\section{2) IS-Created Alienness}

We have emphasized that IS seems to create activities that are broadly alien to the economic and social environment of the community. Alien here applies not only to the factor endowment as such, but refers also to the whole range of characteristics and attributes of a society that affect its capacity to produce goods and services and to respond to unpredicted opportunities (and setbacks). Alienness is not independent of, but also not simply a component of, the distortion issue just discussed.

The clearest case of the point appears in [3] where evidence is presented that Latin American countries exploited the opportunities offered them during World War II in a more effective way than in later years. During the War there was no inflow of physical or financial capital. The countries were forced to use what they had, to build with what they had, and to rely exclusively on their own saving. They did all this in such a manner that productivity rose at a much higher rate than in the postwar period when foreign capital was relied on to a much greater extent. Also domestic resources were much more fully utilized in the War period than after, despite the fact that the rate of capital accumulation was much less. In being forced to use what they had, the economic structure created was much more consistent, much less alien than in later years when IS policies became so paramount.

In Lewis' discussion of changing relative prices and the manner in which costs of new activities in Pakistan decreased shows a similar picture [13]. In activities where the inputs fit well with what Pakistan could offer and could do, relative prices - hence presumably costs - declined. Other sectors, less suitable, were also less successful. Natural resources played some role in this, but certainly the whole story is not simply one of natural resources. 
Sheahan's model of the Colombia economy shows how that economy became more rigid, more dependent on imports as the alienness of its economic structure evolved [23]. This may be contrasted somewhat with Mexico, the structure of which evolved in a manner much more consistent with her social and cultural heritage, entrepreneurial ability, organizing capacity, and management skills.

These matters are difficult to separate from the distortion issue already emphasized. The key point seems to be this: that if a country's economy evolves in a manner consistent with its resource endowment, then that endowment can be near fully exploited.

\section{3) Productivity-Growth Dampening Effects of IS}

The argument above indicated that the conventional approach to IS creates conditions that dampens productivity growth, and rapid productivity growth is essential to a successful IS. So an important positive notion emerging from our studies is that countries must pursue policies that lead to a high productivity growth or IS must fail. The question of course is what are such policies? The first point to emphasise is simply that productivity growth does not just happen. It is not a time trend to be appended. It is rather a phenomenon to be explained, and despite the absence of data and argument it seems clear that it (productivity growth) is and can be affected by economic policies. In many studies where this issue is treated most explicitly, evidence seems to indicate that productivity growth is more likely to reach acceptable rates in economies where distortions and alienness are at a minimum. Certainly it is correct to say that there is nothing incompatible between distortion free economies and the achievement of an acceptable growth of productivity.

Stronger positive statements are more difficult. In general it does seem clear that most developing countries are not paying sufficient attention to the possibilities of adapting and modifying imported physical capital in such a way that it more nearly fits their domestic economies. To do this probably means the allocation of more resources explicitly to this task. It certainly means a conscious recognition of the necessity of this sort of activity by both government and the private sector. General considerations indicate that this can best be done at the firm or plant level. Hence, policies that put pressure on firms or that provide an incentive to them to seek ways to increase the productivity of their resources are an essential ingredient of development policy.

With respect to the effect of education on the productivity of labour, two general points emerge from the literature on education. In the first place, the shortage of the kind of skills learned in the classroom do not appear to be a specific bottleneck. The educational establishment does not turn out individuals who are immediately employed to break a bottleneck. Rather, the productivity 
effect of education is to equip a person to adapt and to respond to opportunities as they appear. Perhaps most directly they equip a person to profit from on-thejob training. The second point has to do with the quality of education. In economies where productivity is generally low, it is unlikely that it is high in the difficult tasks of educating. This means that many countries that are spending large sums on education may be doing it on rather low productivity activities. The not-very-startling idea emerges then that the developing countries may not need more education of the kind currently being provided, but rather improved productivity of the educational activities.

Productivity growth probably is not completely explained by allocation, by technological improvements, and by raising the quality of labour. These, however, are surely a significant part of the key to its understanding. The evidence that productivity growth is a strategic element in the picture of a successful IS policy means, therefore, that these matters are equally a significant part of the key to the devising of effective development policy.

In the preceding sections we have discussed the general content of the usual approach to IS, have tried to identify the specific aspects of that approach that seem to account for the difficulties that so many countries following IS policies find themselves in, and finally we sought to outline in very broad terms what appeared as the more positive findings of our studies. In this final section we seek to consider these positive issues in terms of more specific types of policies and strategies that have emerged.

Few studies suggest a simple laissez-faire, free-trade approach. Simi arly, few deny the advantages of industrialization in particular, or, more ges erally, the importance of changes in the structure of the developing economies and in the composition of their output. More importantly, the idea of a strategy, as defined earlier in this paper, has great merit. There is much evidence that many governments attack the development problem on too many fronts. The consequence of this is not only that demands are placed on the administrative machinery which cannot be met, but also that policies often counter each other and full consequences of all aspects of the attack are not understood (see above item 2, Part B of Section II). Therefore, the notion that the attack on the development objective should consist of a small number of strategic policy areas has great merit. The question of which areas the government should direct its attention depends of course on the assumptions that are made as to how the specific economy functions and as to the nature of the growth mechanism. As emphasized above, the IS strategy as conventionally practised rests on assumptions which recent studies have seriously questioned.

What then can we say about strategic variables and mechanisms of growth on the basis of the preceding discussion of our findings? And what kind of policies exploit these variables and these mechanisms at the same time 
that they induce industrialization and structural changes that are recognized as necessary for development?

Our analysis suggests that three items, distortion, alienness, and productivity growth, are more demanding of attention, i.e., more strategic, than those variables which have occupied attention in the conventional IS model. Since governments cannot do everything, they should then concentrate on these issues. Specific policies would then be appraised as to the extent to which they $i$ ) distort or undistort the system, ii) encourage projects consistent with the other characteristics of the economy, and iii) encourage productivity growth. If policies are successful in these areas, then other conditions necessary for continued growth (e.g., capital formation) may be expected to be induced or to be achievable without major policy measures. To repeat our well-worn theme, it is attacks on these other, these "nonstrategic," growth-producing variables that violate our strategic variables and cause the difficulties which we have found to inhere in the IS strategy.

What kinds of policies make sense in this general context? The following are submitted with brief comments as to policies that are consistent with the above-stated approach to development policy-making.

1) Uniform tariffs. Such tariffs do provide protection, but they tend to minimize the distortion effect of protection, and leave largely to the individual producers to decide what is to be produced and what new activities are to be established. Uniform tariffs do provide incentives for new activities and do serve the primum-mobile function.

2) A possible alternative to the preceding that might be appropriate in some countries is a strong devaluation plus a tax on certain major export items for which foreign demand is inelastic. This approach brings the devaluing country's costs down relative to world costs without sacrificing foreign-exchange earnings from major traditional exports.

3) Subsidies to firms doing research. Research is a risky activity at best, and there are surely external economies in such an activity. It is doubtful if firms will engage in any kind of research without some kind of subsidy. Note the subsidy is to firms. The question of government research institutes is another matter.

4) Tax advantages based on productivity growth. The idea here of course is to encourage productivity growth by means additional to ordinary profit expectations. Note that it is productivity growth that is rewarded not a high productivity. Indeed, a high level of labour productivity in a firm may be due to the use of a technique that, from the economy's point of view, is quite uneconomic. 
5) Tax advantages or subsidies based on labour employed (or tax on capital employed). This is the simplest way to introduce some correction for the common existence of a labour market in which wage rates exceed labour's opportunity cost. One commonly observes, of course, tax advantages or interest subsidies to firms on the basis of investment.

6) Indirect taxes or subsidies aimed at correcting market imperfections. Such taxes can help compensate for monopoly practices, but more generally they can be used to reduce the difference between social and private costs and returns. Examples have to do with electricity use, road use, and tariffs on capital goods.

7) Establishment of activities that provide market information on a wide scale. Such information can help with investment-allocation decisions, with inducement to invest, and with the firm's planning as to production, inventory, etc., all of which add to the efficiency of its operations.

8) Foreign aid to be used to implement policies. Many policies can often be implemented only if there is give in the system to allow for lags. Aid aimed at facilitating the dismantling of controls, of devaluing, or curtailing inflation-producing deficit spending may serve much better than aid to supplement domestic saving or aid to cover all an alleged import gap.

9) A greater emphasis on direct taxes. Direct taxes are the most difficult to enforce, but they also are the most powerful and most discriminating. Countries will not learn to enforce such taxes unless they try to enforce them, and the mere fact that they are now difficult to levy and collect is not a reason for ignoring them and relying heavily on indirect taxes for government revenue purposes.

10) Technical aid aimed at helping people to go about understanding what can be done in the context of their own environment. The tendency in technical aid programmes has been to teach people in poor countries how things are done in rich countries. Our various arguments above have shown that this contributes to the alienness that wo have found so damaging and to the misallocations which we have found equally harmful to the development effort. 


\section{REFERENCES}

1. Bruton, H. J., Export Growth and Import Substitution. Research Memorandum No. 22. (Williamstown, Massachusetts: Williams College, 1968).

2. " "Import Substitution and Productivity Growth", Journal of Development Studies, April 1968.

3. - "Productivity Growth in Latin America", American Economic Review, December 1967.

4. "The Two Gap Approach to Aid and Development", American Economic Review, June 1969.

5. Chenery H. B., and A. M. Strout, "Foreign Assistance and Economic Development", American Economic Review, September 1966.

6. Clark, P. G., Brazilian Import Liberalization. Research Memorandum No. 14. (Williamstown, Massachusetts: Williams College, 1967).

7. Clark, P. G., and R. Weisskoff, Import Demands and Import Policies in Brazil. Research Memorandum No. 8. (Williamstown, Massachusetts: Williams College, 1967).

8. Dobb, M., On Economic Theory and Socialism. (London: Routledge, 1955).

9. Felix, D., "Monetarists, Structuralists, and Import Substituting Industrializing: A Critical Appraisal", in Inflation and Growth in Latin America edited by W. Baer and I. Kerstenetzky. (Homewood, Illinois: 1964).

10. Hirschman, A., The Strategy of Economic Development. (New Haven: Yale University Press, 1958).

11. Khan, A. R., "Import Substitution, Export Expansion, and Consumption Liberalization: A Preliminary Report”, Pakistan Development Review, Vol. III, No 2, Summer 1963.

12. Leibenstein, H., Economic Backwardness and Economic Growth. (New York: Wiley, 1960).

13. Lewis, S. R., Jr., Economic Policy and Industrial Growth in Pakistan. (London: Allen \& Unwin, 1969).

14. _- "Revenue Implications of Changing Industrial Structure: An Empirical Study", National Tax Journal, December 1967.

15. and S. E. Guisinger, "Measuring Protection in a Developing Country: The Case of Pakistan", Journal of Political Economy, October 1968. 
16. Lewis, W. A., "Economic Development with Unlimited Supplies of Labour", Manchester School of Economics and Social Studies, May 1954.

17. Little, I.M.D., "The Strategy of Indian Development", National Institute Economic Review, May 1960.

18. Nurkse, R., Problems of Capital Formation in Underdeveloped Countries. (New York: Oxford University Press, 1958).

19. Power, J. H., "Import Substitution as an Industrialization Strategy", Philippine Economic Journal, Second Semester, 1966.

20. Prebisch, R., "The Economic Development of Latin America and Its Principal Problems", Economic Bulletin for Latin America, February 1962.

21. Reynolds, C. W., Changing Trade Patterns and Trade Policy in Mexico. Research Memorandum No. 17. (Williamstown, Mass.: Williams College, 1967).

22. Rosenstein-Rodan, P., "Problems of Industrialization of Eastern and Southeastern Europe", Economic Journal, June-September 1943.

23. Sheahan, J. B., "Imports, Investment and Growth: Colombia Experience Since 1950" in Development Policy - Theory and Practice edited by Gustav F. Papanek. (Cambridge: Harvard University Press, 1968).

24. Sheahan J., and S. Clark, The Response of Colombia Exports to Variations in Effective Exchange Rates. Research Memorandum No. 11. (Williamstown, Mass.: Williams College, June 1967).

25. Winston, G. C., "A Preliminary Survey of Import Substitution”, Pakistan Development Review, Vol, VII, No. 1, Spring 1967.

26. —Consumer Goods or Capital Goods-Supply Consistency in Development Planning", Pakistan Development Review, Autumn 1967.

27. The Composition of Output and Economic Growth. Research Memorandum No. 24. (Williamstown, Mass.: Williams College, 1968). 